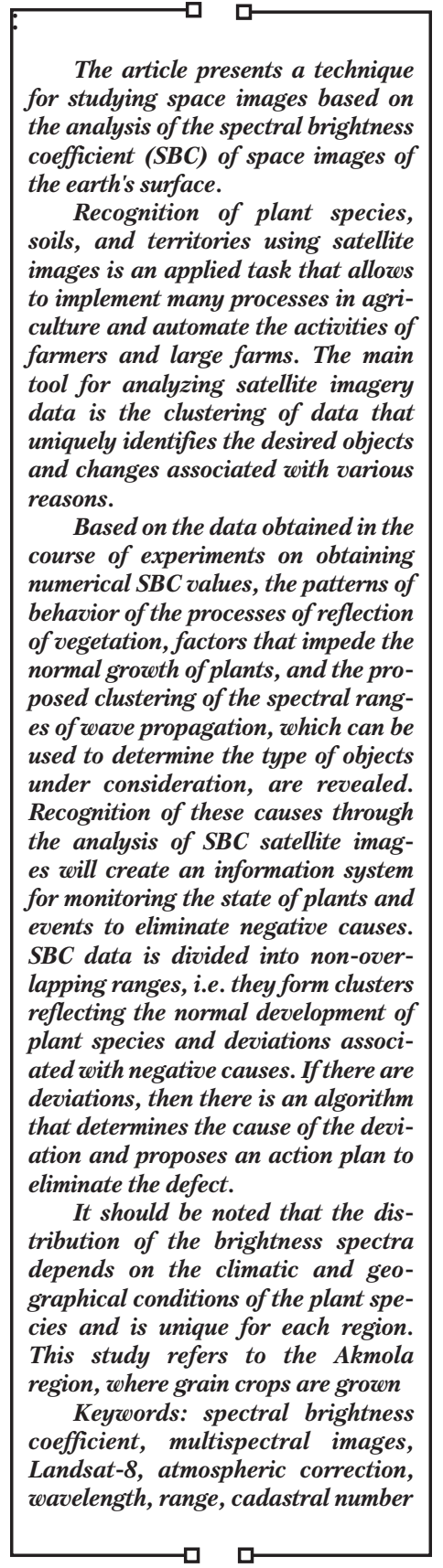

\title{
ANALYSIS OF THE SPECTRAL PROPERTIES OF WHEAT GROWTH IN DIFFERENT VEGETATION PERIODS
}

\author{
Akbota Yerzhanova \\ Corresponding author \\ Doctoral Student* \\ Teacher \\ S. Seifullin Kazakh Agrotechnical University, \\ Pobeda ave., 62, Nur-Sultan, The Republic of Kazakhstan, 010000 \\ E-mail: erjanova_akbota@mail.ru \\ Akmaral Kassymova \\ Associate Professor \\ Department of Information Systems \\ Zhangir Khan University \\ Zhugirkhan str., 51, Uralsk, Republic of Kazakhstan, 090009 \\ GuIzira Abdikerimova \\ $\mathrm{PhD*}$ \\ Manshuk Abdimomynova \\ $\mathrm{PhD}$, Associate Professor \\ Department of Informatics \\ Dulaty University \\ Suleimenova str., 7, Taraz, Republic of Kazakhstan, 080000 \\ Zhuldyz Tashenova
$\mathrm{PhD}^{*}$
EImira Nurlybaeva
$\mathrm{PhD}$ \\ Department of Information Systems \\ T. K. Zhurgenov Kazak National Academy of Arts \\ Panfilova str., 127, Almaty, Republic of Kazakhstan, 050000 \\ *Department of Information Systems \\ L. N. Gumilyov Eurasian National University \\ Satpayev str., 2, Nur-Sultan, Republic of Kazakhstan, 010008
}

Received date 30.10.2021 How to Cite: Yerzhanova, A., Kassymova, A., Abdikerimova, G., Abdimomynova, M., Tashenova, Z., Nurlybaeva, E. (2021). Management of Accepted date 01.12.2021

\section{Introduction}

To analyze the results of remote sensing of the Earth (ERS) and the underlying surface, as a rule, three intervals of the electromagnetic radiation spectrum are distinguished and considered: visible, infrared, and microwave.

When working with multispectral images, "index" images are created by processing the original image to obtain an informative image. Then, based on these values, the "spectral index" of the object is calculated, following which an image is constructed corresponding to the index value in each pixel. This method of creating "index images" will allow the researcher to select an object and assess its condition using graphical data.
In this article, to build an information system, it was necessary to select wave ranges in which it is possible to unambiguously determine plant changes during the growing season.

The research is aimed at creating scientific and technical groundwork in the field of texture-type image processing and processing of agricultural crops for different growing seasons on aerospace images. Agricultural crops and space images of the areas occupied by these crops were previously analyzed on the website https://earthexplorer.usgs.gov/, investigated by the Scientific and Production Center of Grain Farming named after A. I. Baraev. Unfortunately, the processing of these images by agronomists is not informative 
enough due to the fuzziness of the images and the presence of "noise". It should be noted that agricultural crops differ in varieties, soil composition, the presence of weeds, pests inherent in this region, and climatic conditions. Therefore, for each region, it is necessary to compile a database of reference values for each culture and factors affecting the growth of crops. This work represents the implementation of this task for the Akmola region of the Republic of Kazakhstan.

There is no study of the spectral properties of plants and factors that positively or negatively affect plant growth in the Republic of Kazakhstan-

The solution of this problem will allow to analyze the images in detail and can be successfully applied in agricultural fields of science. First of all, this is work with the recognition of crops and factors that negatively affect their growth, using aerospace images.

\section{Literature review and problem statement}

In the work [1], a technique for separating objects by species composition using the ENVI software package was developed and the separation of objects of the same class by the degree of "greenness" makes it possible to fix adverse stress effects on plants. In this work, it is necessary to improve the calculation formulas and data indexes.

The works [2] consider the reflectivity of soils and agricultural crops. However, these results were not considered in terms of creating information systems that distinguished between different types of soil, soil, and crops. For information systems, an algorithm is needed that, based on images, determined various deviations in plant growth, determined a plan of measures to eliminate the causes that interfere with plant growth to obtain the maximum yield within the framework of the unavoidable agroclimatic conditions existing at the time of consideration.

In the work [3] of the conducted studies, the method of field spectrometric work was worked out, which ensures the reliability and comparability of the results of seasonal and long-term observations. SBC measurements and geobotanical studies of plant communities of the Krasnoyarsk Territory and the Republic of Khakassia have been carried out. In the work, the measurements of the SCR were conducted only from 11 to 15 o'clock local time.

Researchers [4] engaged in the identification of weeds and weediness of crops using the remote sensing method, report an insufficient amount of spectral data on crops for some types of weeds and note complex work for accurate determination of spectral data, that is, to combine the remote sensing method with ground-based methods of plant research.

In [5], the values of brightness are considered in different intervals of the electromagnetic spectrum, to obtain informative intervals for the selection of the object under study, for example, for the selection of types of soils and soils, types of vegetation, moisture, damage to crops. This technique for creating graphs of the SBC allows to highlight the type of vegetation or underlying surface, etc. The work used little of the studied satellite image.

The work [6] proved the dependence of the SBC of plant objects on their state. To account for the SBC analysis, satellite imagery was used at least every week. Various approaches have been used to process multispectral satellite images for more reliable recognition of different classes of vegetation. In this work, it is necessary to improve the action plan to eliminate negative factors.

Operational Land Imager (OLI) [7] collects image data for nine shortwave spectral bands with a spatial resolution of $30 \mathrm{~m}$ for all bands except the 15-meter panchromatic band. Our work shows seven channels. Table 1 shows the Landsat-8 OLI channels, the frequency range, the center of the range, the spatial resolution, and the signal-to-noise ratio (SNR) at the reference brightness. The disadvantage of this work is that the resolution of Landsat 8 OLI is average.

Table 1

$\mathrm{OLI}+$ spectral bands

\begin{tabular}{|c|c|c|c|}
\hline Spectral Band & $\begin{array}{c}\text { Frequency } \\
\text { range }(\mu \mathrm{m})\end{array}$ & $\begin{array}{c}\text { Range cen- } \\
\text { ter }(\mu \mathrm{m})\end{array}$ & $\begin{array}{c}\text { Spatial reso- } \\
\text { lution }(\mathrm{m})\end{array}$ \\
\hline $\begin{array}{c}\text { Band 1 - Coast and } \\
\text { aerosols }\end{array}$ & $0.43-0.45$ & 0.44 & 30 \\
\hline Band 2 - Clue & $0.45-0.52$ & 0.48 & 30 \\
\hline Band 3 - Green & $0.53-0.60$ & 0.56 & 30 \\
\hline Band 4 - Red & $0.63-0.68$ & 0.66 & 30 \\
\hline Band 5 - NIR & $0.85-0.89$ & 0.87 & 30 \\
\hline Band 6 -SWIR 1 & $1.56-1.66$ & 1.61 & 30 \\
\hline Band 7 -SWIR 2 & $2.1-2.3$ & 2.2 & 30 \\
\hline
\end{tabular}

In the work [8], the authors identified clusters on multispectral images, and these clusters allow using minimal computing resources. They use only the values of the SBC and the clusters chosen by them, which requires minimal computational resources.

Summing up this section, let's note that the use of vegetation is one of the most well-established values for the study of satellite images for the recognition of types of crops, soils and negatively influencing factors on plant growth, etc.; numerous studies have been conducted and improved methods for recognizing types of vegetation and factors negatively affecting plant growth.

However, the most effective values are those using texture features for clustering satellite images.

\section{The aim and objectives of research}

The aim of the study is development of an integrated approach for the classification of crops by vegetation based on the analysis of satellite images using textural features, to take into account a large number of textural features, analysis of spectral brightness coefficients, to eventually this will create a program applicable to a wide class of crop production problems.

To achieve this goal, the following tasks are being solved:

- analyze multispectral image processing;

- process multispectral images based on SBC for growing seasons;

- analyze clustered satellite images by texture features.

\section{Materials and methods}

The article identifies clusters in multispectral images and establishes that using only the values of the SBC and the selected clusters, these clusters allow the minimum computing power. 
The ENVI software complex, thanks to the programming language IDL (Interactive Data Language), is capable of performing complex work on image processing from multispectral and hyperspectral imaging systems. Many image analysis algorithms in the ENVI software package have been specially designed for processing large amounts of information and are used in hyperspectral images. Most of these algorithms can also be used to work with multispectral images.

The peculiarity of using space images to study objects on the earth's surface is that between the elements of the earth's cover and the recording equipment there is a layer of the atmosphere and clouds. The presence of an intermediate medium causes several difficulties: absorption by the atmosphere of sunlight of certain wavelengths, scattering of rays, the influence of atmospheric haze, the screening effect of cloudiness, and others.

The state of the atmosphere affects the brightness values recorded by the imaging system in two ways: by scattering and absorbing energy. If the field of view is very large, then part of the scattered radiation will still be perceived by the imaging system, in which case the signal is amplified, and the image brightness is increased.

To perform atmospheric correction, it is necessary to know such parameters as the amount of water vapor, aerosols, visibility, etc. Direct measurement of these atmospheric parameters is rarely performed by methods of obtaining them from spectral brightness values. The resulting coefficients are used to define highly accurate atmospheric correction models that are used to process the data [9].

Dates of satellite imagery measurements in the area of interest and OLI data collection are shown in Table 2.

Remote sensing has proven useful for obtaining information about crops. However, obtaining reliable information from remote sensing data is challenging because the signal detected by the sensor is sensitive to atmospheric influences. The scattering and absorption of molecules and aerosols present in the atmosphere change the total reflectivity emanating from the target. Many atmospheric correction algorithms have been developed to eliminate these undesirable effects, however, several correction procedures are sensor dependent and designed for land use [10].

For further research, let's use a satellite image with atmospheric correction in the Shortandy village, Akmola region (Fig. 1), using fields with cadastral number 01-012-025-040:42 [11].

Thus, to create reliable maps of vegetation at the local level, it is necessary to develop a technique for automatic decoding of vegetation cover objects, based on the justification of the expediency of using multi-seasonal data using quantitative characteristics, determining the optimal amount and the moment of appearance of obtaining zonal space images.

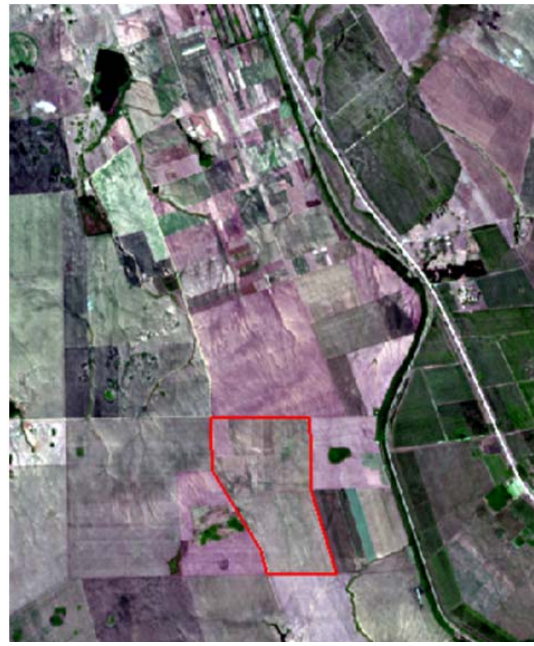

Fig. 1. Satellite image of wheat by cadastral number 01-012-025-040:42

When analyzing aerospace images, researchers also deal with different textures. According to textural features, it is possible to determine soils, perennial grasses, fields sown with grain or legume plants, etc. It is also possible to distinguish agricultural crops affected by pests, weeds, deserted territories.

Thus, the sources of images can be different. The ultimate goal of the work is to determine a set of informative features on an aerospace image.

The work uses about 20 sets of textural features and the data of the SBC for different growing seasons.

The task of analyzing aerospace observations is very difficult if spectral portraits of objects on the Earth's surface are used.

In [12], the texture is understood as "the spatial organization of elements in a certain area of the surface". It also explains that this organization is due to a certain statistical distribution of the intensity of gray tones or tones of different colors. A plot can be considered textural if the number of intensity differences or color changes noted on it is large enough. In [13], a texture is called "some organized area of the surface". In [14], a texture is defined as a matrix or fragment of spatial properties of images with homogeneous statistical characteristics.

Textures can be divided into several classes as follows:

1) by origin: artificial - for example, graphic patterns, and natural - for example, grass, forest, earth;

2) by surface structure: structural, consisting of geometrically regular repeating elements, and stochastic, formed by a sequence of random elements; by the relative sizes of texture elements: fine-grained and coarse-grained;

3 ) according to the shape of the texture elements: wavy, spotted, irregular, ruled, and so on [12].

Table 2

Land plot, date and time of satellite image agriculture

\begin{tabular}{|c|c|c|c|c|c|}
\hline $\begin{array}{c}\text { Location of the } \\
\text { investigated } \\
\text { object }\end{array}$ & $\begin{array}{l}\text { Cadastral number of } \\
\text { the investigated object }\end{array}$ & $\begin{array}{l}\text { Land } \\
\text { category }\end{array}$ & OLI Image & $\begin{array}{c}\text { Date of } \\
\text { purchase }\end{array}$ & Time \\
\hline \multirow{5}{*}{$\begin{array}{l}\text { Akmola region } \\
\text { village of } \\
\text { Shortandy }\end{array}$} & \multirow{5}{*}{ 01-012-025-040:42 } & \multirow{5}{*}{$\begin{array}{l}\text { Agricul- } \\
\text { tural land }\end{array}$} & LC08_L1TP_156024_20210525_20210529_01_T1.tar & 25-05-2021 & 06:13:58 \\
\hline & & & LC08_L1TP_156024_20210610_20210615_01_T1.tar & 10-06-2021 & 06:14:05 \\
\hline & & & LC08_L1TP_155024_20210721_20210729_01_T1.tar & 21-07-2021 & 06:08:04 \\
\hline & & & LC08_L1TP_155024_20210806_20210811_01_T1.tar & 08-06-2021 & 06:08:11 \\
\hline & & & LC08_L1TP_156024_20210914_20210924_01_T1.tar & 14-09-2021 & 06:14:33 \\
\hline
\end{tabular}


From the above definitions and characteristics, it follows that a texture is a certain area of the image, one that has homogeneous statistical characteristics. This means that each texture of this class can be described using a characteristic property common to all textures of this class [12]. Such properties are called textural features [15]. Texture features play an important role when dividing an image into separate areas. For example, satellite images can distinguish fields where cereals or legumes grow, distinguish deciduous or coniferous forests, etc.

The standard approach for calculating texture features is as follows. It is necessary to select the so-called running window with an odd side: $3,5,7$ pixels. The attribute is calculated inside the running window. The size of the local fragment is the carrier of texture properties. The attribute value is written to a new matrix of the same size as the original one. In the new matrix, the value is written to a point with coordinates equal to the coordinates of the center of the running window. The elements of the new matrix are obtained in a certain interval $[\mathrm{A}, \mathrm{B}]$. Then usually this interval is linearly mapped to the segment $[0,255]$. After that, it is possible to visualize the result of calculating the texture feature.

Experiments have shown that the standard approach in our case is uninformative. Therefore, it was decided to use a non-standard approach. Namely, texture features are calculated from large windows (including non-square ones), which the user can set by selecting an area that may be of interest to it. That is, it is about calculating numerical characteristics related to vast areas, including various kinds of artifacts.

The 10 most important textural features are considered (Fig. 4-8). Table 3 below shows some of them

Table 3
The resulting image will be processed in the ENVI software package (SP). The SP is capable of providing a full range of work on processing images from multispectral and hyperspectral shooting systems. Many image analysis algorithms in the ENVI software package have been specially developed for processing large amounts of information (Radiance, FLAASH, SBC, NDVI) contained in hyperspectral images.

Then let's carry out secondary image processing. Spectral portraits do not always provide reliable information as they depend on many physical, climatic, and geographical factors. To increase the adequacy of the decisions made, it is necessary to use the contextual information of the images themselves. One of the sources of contextual information is the concept of texture, which is a function of a set of pixels of a fragment. For example, more than two hundred textural features are known, and about fifty are usually cited in scientific reviews. At the same time, when processing satellite images, as a rule, $3-4$ signs are used. Such several textural features is not enough to decide for the tasks of the proposed project due to insufficient information.

Image segmentation can be carried out locally and globally. The local method evaluates the presence of a boundary between regions by the behavior of features in the vicinity of the image point. The global method involves preliminary clustering of the feature space and then establishing a correspondence between the image pixel and the cluster into which its feature vector falls [16]. One of the heuristic clustering methods is methods based on a sequential agglomerative procedure. The advantage of these methods is the simplicity of the computational procedure and algorithms.

Clustering was performed using vector texture features. The stages of clustering satellite images are shown in Fig. 2.

\begin{tabular}{|c|c|}
\multicolumn{2}{c}{ Examples of textural features } \\
\hline $\begin{array}{c}\text { Signs based on statis- } \\
\text { tical characteristics }\end{array}$ & $\begin{array}{c}\text { Signs that take into account } \\
\text { the mutual location }\end{array}$ \\
\hline $\begin{array}{c}k \text {-th initial moment } \\
\text { Average }\end{array}$ & $T_{1}^{k}=n^{-2} \sum_{i=1}^{n} \sum_{j=1}^{n}[f(i, j)]^{k}$. \\
Entropy & $T_{1}=\mu_{i}=\mu_{j}=\sum_{i=0}^{N-1}\left[i \sum_{j=0}^{N-1} P(i, j)\right]$. \\
$T_{2}=-\sum_{g=0}^{N-1} F(g) \log _{10} F(g)$. & $T_{2}=\sum_{i=0}^{N-1 N-1} \sum_{j=0}^{N-1}[P(i, j)]^{2}$. \\
$T_{3}=\sum_{k=0}^{N-1}[F(g)]^{2}$. & $T_{3}=\sigma_{i}^{2}=\sum_{i=0}^{N-1}\left[\left(i-\mu_{2}\right)^{2} \sum_{j=0}^{N-1} P(i, j)\right]$. \\
$T_{4}=-\sum_{g=0}^{N-1}(g-\mu)^{2} F(g)$. & $T_{4}=\sum_{i=0}^{N-1 N-1} \sum_{j=0} P(i, j) /(1+|i-j|)$. \\
\hline
\end{tabular}

\section{Results stages of clustering satellite images}

\section{1. Analysis of multispectral image processing}

On the Earth Explorer website, let's get multispectral images. The site is one of the main and free sources of remote sensing materials. Access to it is possible both for simple viewing of the catalog and for direct receipt of the materials stored in it. In the second case, registration on the archive's website will be required.

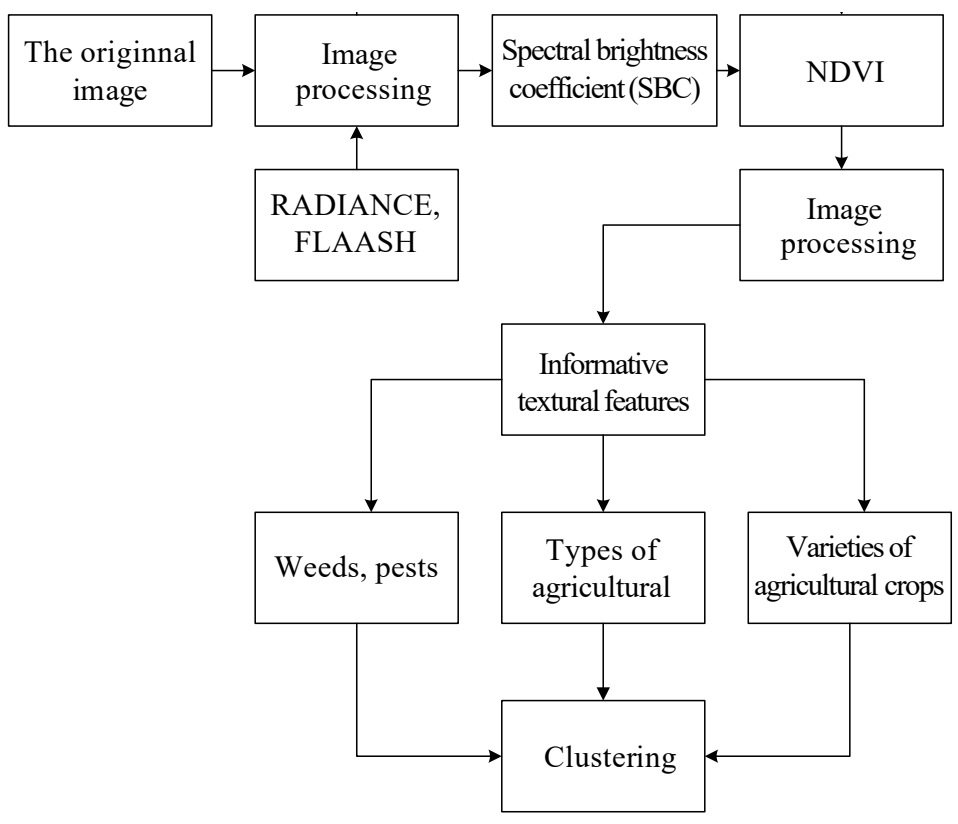

Fig. 2. Stages of clustering satellite images

5. 2. Processing of multispectral images based on SBC for growing seasons

The possibility of simultaneous shooting in several ranges is an important advantage of remote sensing methods for studying the earth's surface, including vegetation. Each spectral band has different information content and is suit- 
able for solving various problems in the study of vegetation: estimating the volume of plant biomass and crop yields, determining the amount of moisture in plants, and identifying plant communities prone to drought or waterlogging, vegetation affected by the disease, etc. [17].

For visual analysis of the state of agricultural land, the most representative is synthesis options using the near-infrared spectrum. Images in infrared wavelength are sufficiently contrasting and allow the most reliable separation of open ground from developing seedlings and analysis of their condition. Fig. 3 shows the same farming in different growing seasons with natural colors. tween 12-21.05.2021. It can be said that the study of crops in Fig. $4, a, b$ is uninformative.

Fig. 5, $a, b$ shows that agricultural crops are already growing and it is possible to see the allocation of farmland boundaries. But the image is not informative for further research.

In Fig. 6, 7 the textural signs show wheat growth very well. Before the ripening of wheat, during the growing season from 21.07.2021 to 06.08.2021, wheat growth is visible from satellite images, by the skin, and by texture.

The study showed that for determining the growth and types of crops, identifying weeds, pests are informative in the last trimester of the growing season.

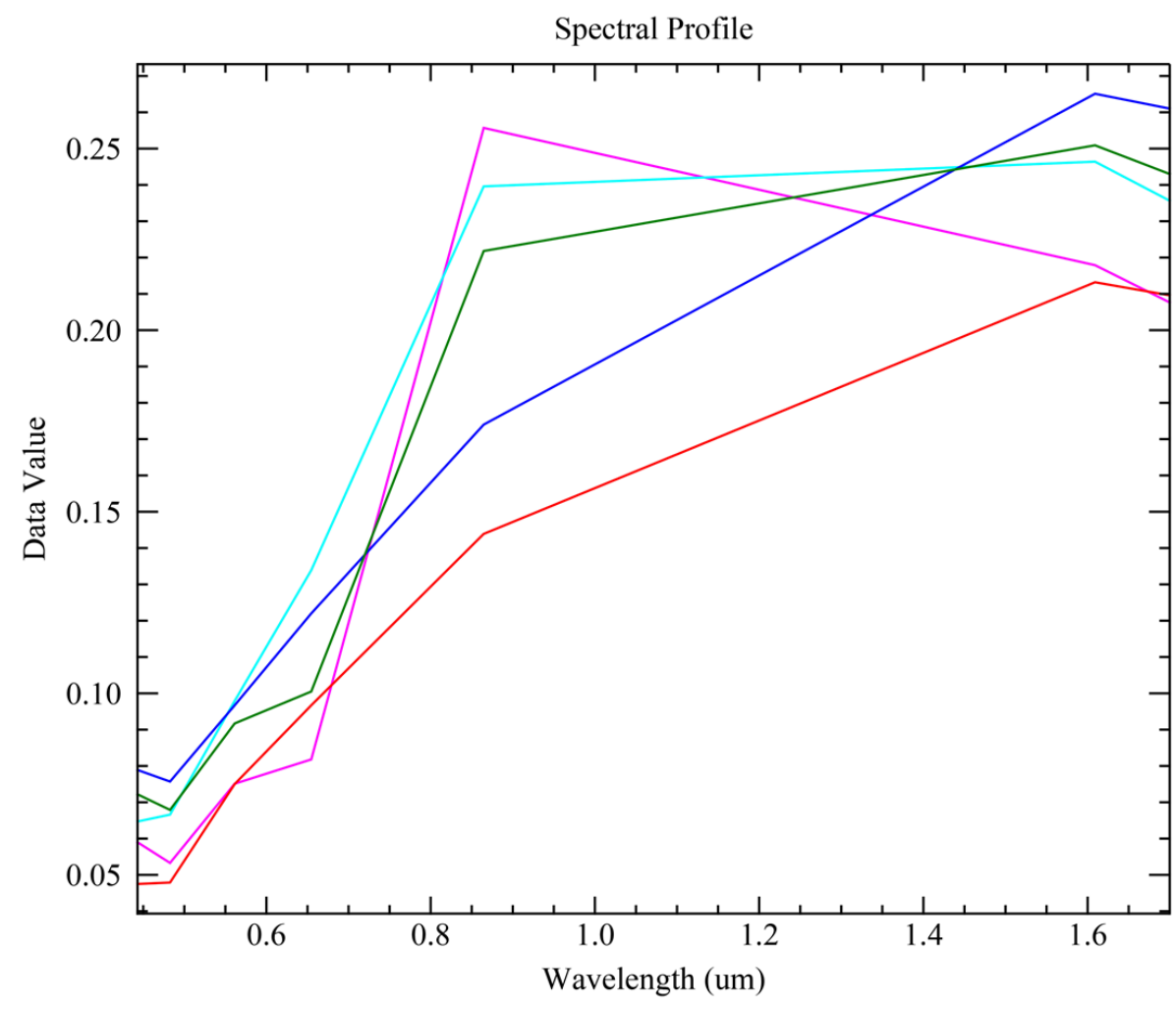

Fig. 3. SBC of wheat for the growing season from 25.05.2021 to 14.09 .2021

Fig. 3 shows a graph of wheat SBC in the wavelength range of 0.44-1.7 microns. This image was taken on the Landsat 8 OLI satellite during the growing season from 25.05.2021 to 14.09.2021. Wheat sowing was carried out on 12-25.05.2021. In the graph, it is possible to see that in the wavelength range of 0.85 microns, the lines are divided into non-overlapping SBC ranges.

To analyze space images, it is necessary to use images of the snowless period.

\section{3. Analysis of clustered satellite images by texture} features.

Synthesis of SWIR-NIR-R channels is widely used to study vegetation cover. The combination gives a lot of information and color contrasts, for example, healthy vegetation looks bright green, and soils look pinkish-purple. This combination makes it possible to better distinguish and analyze agricultural crops.

Fig. 4, $a$ shows a satellite image taken from the LANDSAT-8 OLI satellite. In this image, only the soil is visible (pinkish-purple color), since wheat was sown be-

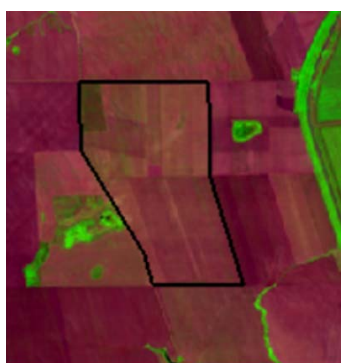

$a$

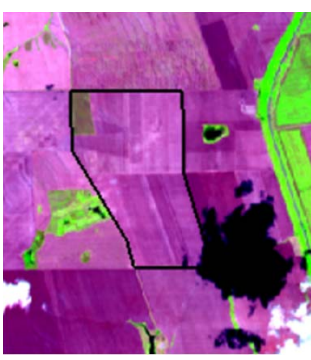

$a$

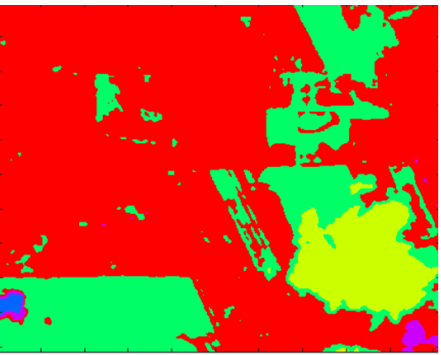

$b$

Fig. 4. The image of the object under study by date 25.05 .2021 : $a$ - original image;

$b$-clustered image with textural features

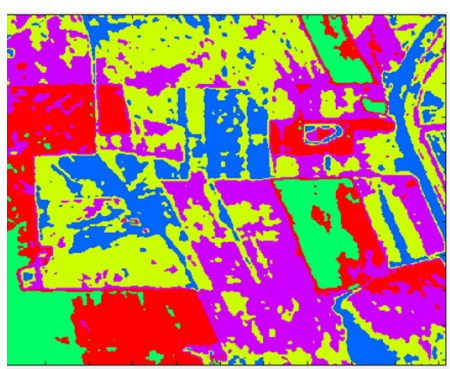

$b$
Fig. 5. The image of the object under study by date 10.06.2021: $a$ - original image; $b$-clustered image with textural features

Wheat harvesting was carried out between 18.08 15.09.2021. In the study area, Fig. 8 shows an empty, cleaned field. 


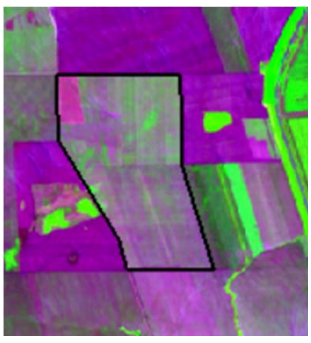

$a$

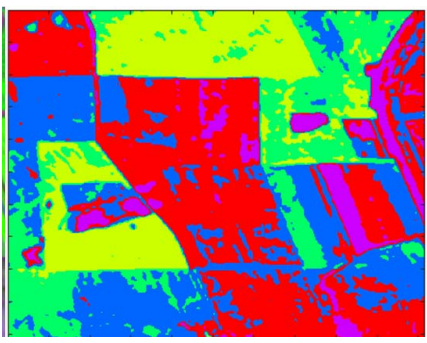

$b$
Fig. 6 . The image of the object under study by date 21.07.2021: $a$ - original image;

$b$-clustered image with textural features

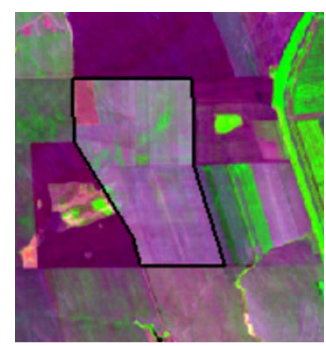

a

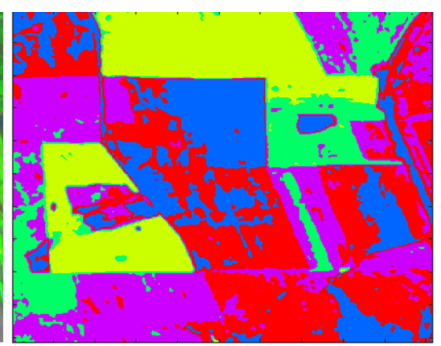

$b$
Fig. 7. The image of the object under study by date 06.08.2021: $a$ - original image;

$b$-clustered image with textural features

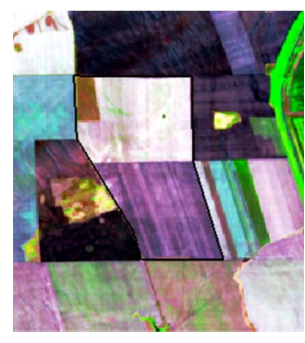

a

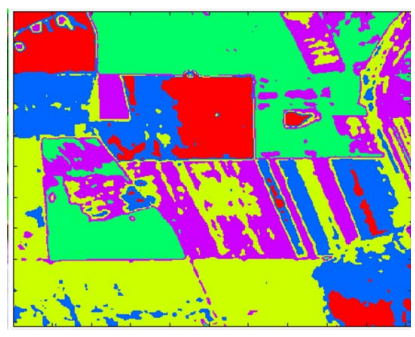

b
Fig. 8. The image of the object under study by date 14.09.2021: $a$ - original image;

$b$-clustered image with textural features

\section{Discussion of clustering results for the growing season}

The use of digital image processing technologies makes it possible to develop a system for recognizing crops, factors affecting plant growth, as well as an information system that allows agricultural producers to carry out the necessary agrotechnical measures to obtain a high yield, with minimal participation of specialists such as agronomists, soil scientists, hydrologists, and others.

Thus, the developed information system optimizes the costs of attracting third-party specialists, as well as timely carrying out agrotechnical measures.
When compiling the database, we were engaged in the collection and processing of data from open sources, where the SBC of crops, soils, and other factors are considered [11]. Consideration of various areas of agricultural crops is associated with a lack of data required for the research tasks.

The proposed models, methods, and algorithms in the form of a prototype of an information system can be applied by agricultural producers to carry out the necessary agrotechnical measures to obtain a high yield, with minimal participation of specialists such as agronomists, soil scientists, hydrologists, and others.

Based on the research results, the information system allows for effective management of an agricultural enterprise and optimizes the costs of attracting third-party specialists, as well as timely conduct agrotechnical measures (Fig. 2, 3).

To analyze the results of remote sensing of the Earth (RSE) and the underlying surface, as a rule, three intervals of the spectrum of electromagnetic radiation are distinguished and considered: visible, infrared, and microwave.

In this paper, the values of brightness in different intervals of the electromagnetic spectrum are considered, to obtain informative intervals for the selection of the object under study, for example, for the selection of types of soils and soils, types of vegetation, moisture, damage to agricultural crops [5,6]. This technique for creating graphs of the SBC allows to highlight the type of vegetation or underlying surface, etc.

There are the following disadvantages in the work, these are: images from the Landsat- 8 satellite are taken 1 time in 2 weeks; when clustering the image, there is interference, cloud cover, noise, etc.

In the future, let's continue the research with UAVs and ground-based spectrometers to obtain an accurate result.

\section{Conclusion}

1. Experimental studies have been carried out to obtain multispectral images from a satellite image for classification. The work was carried out in the ENVI 5.3 environment. Spectral values were plotted for 3 channels using the SBC created for each object for the growing season.

2. A program has been implemented that allows clustering definitions of the type of crops and types of underlying surface such as soil, water, and others. The crop recognition was examined by two fixed points of $0.55 \mu \mathrm{m}$ and a point of $0.66-0.68 \mu \mathrm{m}$ for the presence of extremes. For other underlying surfaces such as soil, water, etc., there are other fixed points.

3. An algorithm has been developed that allows clustering of crop species at different stages of the growing season together with SBC in the red and infrared wave ranges. The differences in SBC vegetation are obvious when analyzing SBC. According to the results of data analysis, recognition of agricultural crops is informative after the use of vector textural clustering features.

\section{References}

1. Fisenko, E. V. (2019). Analysis of the results of using the technique of multimedia processing of spectral images of the underlying surface using complex remote sensing data. Geodesy and Aerophotosurveying, 63 (3), 324-332. doi: https://doi.org/10.30533/ 0536-101x-2019-63-3-324-332 
2. Bajsholanov, S. S., Polevoj, A. N. (2016). Ocenka vlagoobespechennosti vegetacionnogo perioda v severnoj zernoseyushchej territorii Kazahstana. Fizicheskaya geografiya i geomorfologiya, 3 (83), 95-102.

3. Botvich, I. Yu., Volkova, A. I., Kononova, N. A., Ivanova, Yu. D., Shevyrnogov, A. P. (2017). Spectrometry of herbaceous vegetation of the krasnoyarsky krai and Republic of Khakassia: the method of measurement, storage and processing of data. Reshetnevskie chteniya, 398-400. Available at: https://cyberleninka.ru/article/n/spektrometrirovanie-travyanistoy-rastitelnostikrasnoyarskogo-kraya-i-respubliki-hakasiya-metodika-izmereniy-hranenie-i-obrabotka

4. Danilov, R. Yu., Kremneva, O. Yu., Ismailov, V. Ya., Tretyakov, V. A., Rizvanov, A. A., V.V. Krivoshein, Pachkin, A. A. (2020). General methods and results of ground hyperspectral studies of seasonal changes in the reflective properties of crops and certain types of weeds. Sovremennye Problemy Distantsionnogo Zondirovaniya Zemli Iz Kosmosa, 17 (1), 113-127. doi: https://doi.org/ 10.21046/2070-7401-2020-17-1-113-127

5. Yerzhanova, A. Ye., Kerimkhulle, S. Ye., Makhanov, M., Abdikerimova, G. B., Beglerova, S. T., Taszhurekova, Zh. K. (2021). Atmospheric correction of Landsat-8 / OLI data using the FLAASH algorithm: obtaining information about agricultural crops. Journal of Theoretical and Applied Information Technology, 99 (13), 3110-3119. Available at: http://www.jatit.org/volumes/ Vol99No13/3Vol99No13.pdf

6. Yerzhanova, A. Y. (2021). Spectral properties of plants by vegetation periods for analysis of satellite images. Vestnik KazNRTU, 143 (1), 226-232. doi: https://doi.org/10.51301/vest.su.2021.v143.11.28

7. De Keukelaere, L., Sterckx, S., Adriaensen, S., Knaeps, E., Reusen, I., Giardino, C. et. al. (2018). Atmospheric correction of Landsat-8/OLI and Sentinel-2/MSI data using iCOR algorithm: validation for coastal and inland waters. European Journal of Remote Sensing, 51 (1), 525-542. doi: https://doi.org/10.1080/22797254.2018.1457937

8. Stycenko, E. A. (2018). Razrabotka metodiki avtomaticheskoj rasshifrovki rastitel'nogo pokrova s kompleksnym ispol'zovaniem mnogosezonnyh zonal'nyh kosmicheskih snimkov. Moscow, 213.

9. Kruse, F. A. (1988). Use of airborne imaging spectrometer data to map minerals associated with hydrothermally altered rocks in the northern grapevine mountains, Nevada, and California. Remote Sensing of Environment, 24 (1), 31-51. doi: https://doi.org/ 10.1016/0034-4257(88)90004-1

10. Kolesnikova, O., Cherepanov, A. (2009). Vozmozhnosti PK ENVI dlya obrabotki mul'tispektral'nyh i giperspektral'nyh dannyh. Geomatika, 3, 24-27. Available at: https://sovzond.ru/upload/iblock/65b/2009_03_004.pdf

11. EarthExplorer. Available at: https://earthexplorer.usgs.gov/

12. Andreev, G. A., Bazarskiy, O. V., Glauberman, A. S., Kolesnikov, A. I., Korzhik, Yu. V., Khlyavich, Ya. L. (1984). Analiz i sintez sluchaynykh prostranstvennykh tekstur. Zarubezhnaya radioelektronika, 2, 3-33.

13. Kharalik, R. M. (1979). Statisticheskiy i strukturnyy podkhody k opisaniyu tekstur. TIIER, 67 (5), 98-119.

14. Potapov, A. A. (2003). Novye informatsionnye tekhnologii na osnove veroyatnostnykh teksturnykh i fraktal'nykh priznakov v radiolokatsionnom obnaruzhenii malokontrastnykh tseley. Radiotekhnika i elektronika, 48 (9), 1101-1119.

15. Kolodnikova, N. V. (2004). Obzor teksturnykh priznakov dlya zadach raspoznavaniya obrazov. Doklady Tomskogo gosudarstvennogo universiteta sistem upravleniya i radioelektroniki, 113-124.

16. Sidorova, V. S. (2012). Hierarchical cluster algorithm for remote sensing data of earth. Pattern Recognition and Image Analysis, 22 (2), 373-379. doi: https://doi.org/10.1134/s1054661812020149

17. Irons, J. R., Dwyer, J. L., Barsi, J. A. (2012). The next Landsat satellite: The Landsat Data Continuity Mission. Remote Sensing of Environment, 122, 11-21. doi: https://doi.org/10.1016/j.rse.2011.08.026 